\title{
Characterization of Cystic Lesions of Pancreas by Computed Tomography Scan- A Retrospective Study
}

\author{
Rajoo Ramachandran¹, Kumaresh Athiyappan², Prabhu Radhan Radhakrishnan³, Ananda Kumar Balasubramanian \\ ${ }^{1}$ Department of Radiology, Sri Ramachandra Institute of Higher Education and Research, Chennai, Tamilnadu, India. \\ 2Department of Radiology, Sri Ramachandra Institute of Higher Education and Research, Chennai, Tamilnadu, India. \\ ${ }^{3}$ Department of Radiology, Sri Ramachandra Institute of Higher Education and Research, Chennai, Tamilnadu, India. \\ ${ }^{4}$ Department of Radiology, Sri Ramachandra Institute of Higher Education and Research, Chennai, Tamilnadu, India.
}

\section{ABSTRACT}

\section{BACKGROUND}

Cystic lesions of the pancreas consist of both neoplastic and non-neoplastic lesions. Computed tomography (CT) scan is commonly used in imaging cystic lesions of pancreas as it is easily available and less time consuming. In this study, we evaluate the different characteristic features of cystic lesions of pancreas and differentiate them based on imaging.

\section{METHODS}

This is a retrospective study done over a period of 5 years. 94 patients with cystic lesions of pancreas were selected and analysed. All patients had proven final diagnosis by surgery, by endoscopy guided aspiration or by follow up. Various parameters of the cysts were studied like the age and sex distribution, incidence, size of the lesion, location, thickness of septations, nature of calcification, pancreatic duct dilatation if any, size of the largest cyst within the lesion, approximate number of cysts, presence of any solid component, nature of enhancement, presence of the wall and contour of the lesion. Descriptive statistics like percentage was used and each cyst was differentiated based on the above features.

\section{RESULTS}

Overall, pseudocysts were the commonest cysts, and all were associated with pancreatitis. They were commonly seen in the middle-aged males. Serous cystadenomas were the commonest neoplastic cysts. Benign neoplastic cysts were common in females and malignant neoplastic cysts were common in males. Serous cystadenomas were common in head of the pancreas whereas mucinous cystadenomas were common in tail of the pancreas. All solid pseudo papillary epithelial neoplasm (SPEN) were seen in the tail of the pancreas. No difference in each cyst based on overall size was seen. Mucinous cystadenomas showed fewer but bigger cysts within the lesion compared to serous cystadenomas. Peripheral wall calcification was seen in mucinous cystadenomas whereas central calcifications were seen in serous cystadenomas. Communication with a dilated pancreatic duct and bulging papillae was seen in intraductal papillary mucinous tumour (IPMT). Most of IPMT and serous cystadenomas showed a lobulated invisible wall whereas mucinous cystadenomas showed a smooth visible wall. All malignant cysts were associated with solid component and thick septations.

\section{CONCLUSIONS}

CT scans helps us to diagnose various cystic lesions of pancreas based on different characteristic imaging features.

\section{KEY WORDS}

CT, Cystic Lesions, Pancreas
Corresponding Author:

Dr. Kumaresh Athiyappan, Associate Professor,

Department of Radiology, Sri Ramachandra Institute of Higher Education and Research, Porur, Chennai-600116, Tamilnadu, India. E-mail: drkumaresha@gmail.com

DOI: 10.14260/jemds/2020/158

Financial or Other Competing Interests: None.

How to Cite This Article:

Ramachandran $R$, Athiyappan $K$, Radhakrishnan PR, et al. Characterization of cystic lesions of pancreas by computed tomography scan- a retrospective study. J. Evolution Med. Dent. Sci. 2020;9(10):726730, DOI: 10.14260/jemds/2020/158

Submission 13-01-2020,

Peer Review 20-02-2020,

Acceptance 22-02-2020,

Published 09-03-2020.

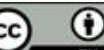




\section{BACKGROUND}

Diagnosis of cystic lesions of pancreas in the contemporary generation are rapidly escalating. Substantial number of cystic lesions have been recognized due to recent evolution and persistent use of imaging modalities.[1] Accurate characterization of cystic lesions is necessary to discriminate cystic neoplasms of pancreas from pseudocysts, as they are widely misdiagnosed.[2] For inceptive identification, characterization of pancreatic cysts, Multi-detector computed tomography is the desired imaging modality. ${ }^{[3]}$ Morphological hallmark of cyst, as well as primacy of demonstrating the connection of cyst to pancreatic duct is seen best on Magnetic resonance imaging.[4] The cystic lesions of pancreas can be classified as non-neoplastic and neoplastic lesions. [5] The non-neoplastic lesions include pseudocysts. The commonest cystic neoplasms are intraductal papillary mucinous neoplasm (IPMT), serous cystic neoplasm and mucinous cystic neoplasm. Uncommon cystic neoplasms are solid pseudopapillary epithelial neoplasm (SPEN). Solid pancreatic lesions with cystic degeneration include pancreatic adenocarcinoma, cystic islet cell tumour, metastasis, cystic teratoma and sarcoma.

Ultrasonography is usually the initial investigation done to evaluate the cystic lesions of the pancreas. Ultrasonography is good in demonstrating the internal features of the cyst like septations, vascularity, mural nodule and contents of the cyst. However, its uses are limited due to overlying bowel gas shadows and in obese patients. Recently, endoscopic ultrasound helps in detailed high-resolution imaging of the cyst with advantage of diagnostic aspiration and analysis of the fluid from the cyst.[6] Multidetector CT scan and magnetic resonance imaging (MRI) are commonly used to evaluate the internal architecture and enhancement characteristics of cystic lesions of the pancreas. CT is useful to find calcifications within the cyst. MRI has good soft tissue resolution and is useful to see the communication between the cyst and the pancreatic duct. Secretin stimulated MR cholangiopancreatography can be done for better visualization of the communication between the cyst and the pancreatic duct which helps to differentiate IPMT from other tumours. ${ }^{[7]}$

It is important to differentiate cystic lesions of the pancreas because mucinous lesions like mucinous cystadenoma and IPMT have malignant potential. Unless there are contraindications to surgery all mucinous cystic lesions should be excised. The benign and low-grade malignant tumours like serous cystadenoma and SPEN can be followed up in asymptomatic patients. However, the lesion should be excised in doubtful diagnosis or when seen in symptomatic patients. [8] Pseudocysts of the pancreas are the most common cystic lesions of the pancreas with a history of acute/chronic pancreatitis or other risk factors. In general, clinical history and imaging features establish the diagnosis of a pseudocyst. A pseudocyst of the pancreas is seen on computed tomography as an oval or round cyst with a thin enhancing fibrous capsule measuring $1-2 \mathrm{~mm}$ thickness. They contain fluid with a density of $>20 \mathrm{HU}$. [9]

Serous cystadenomas are seen in the head and neck of the pancreas with the tumour size ranging between $1-20 \mathrm{~cm}$ with an average size of $6 \mathrm{~cm}$. Common features of serous cystadenoma include fine or external lobulation, enhancement of septa and wall of the cyst . A characteristic enhancing central scar with or without the association of calcifications is seen. In some cases, these neoplasms are comprised of micro cysts arranged in honeycomb fashion. ${ }^{[10]}$ Mucinous cystadenoma is commonly seen in the body and tail of the pancreas. They present as multilocular macro cysts with a mean diameter ranging from $7-10 \mathrm{~cm}$. The wall of the cyst is $1-2 \mathrm{~mm}$ thick and, in few cases, may contain mural calcification. Surgical resection is recommended since mucinous cystadenoma has a high-risk potential for malignancy.[11]

Intraductal papillary mucinous neoplasm (IPMN) is classified into three types- Main duct, branch type, and mixed type. Main duct type presents as diffuse or segmental duct dilation and has the highest malignant potential. Branch type is mostly seen in head of pancreas and present as a unilocular or multifocal cysts communicating with the main pancreatic duct. MRCP plays a vital role in demonstrating the communication between the cyst and duct. Imaging features concerning for malignancy are duct dilatation $>5 \mathrm{~mm}$, enhancing mural nodule $>5 \mathrm{~mm}$, cyst diameter $>3 \mathrm{~cm}$ and thick enhancing wall. [12] Solid pseudopapillary neoplasms are frequently seen in the female population with a mean age 25 years. On imaging, they appear as well-defined mass with solid-cystic areas with necrosis and haemorrhagic debris. Solid pseudopapillary neoplasms are low-grade neoplasms with excellent prognosis noted in most patients. [13] True epithelial cysts of the pancreas are very rare and are seen in syndromes like Von Hippel Lindau syndrome. [14]

\section{METHODS}

In this retrospective study, all patients with proven cystic lesions of pancreas who underwent CT imaging using a 64 slice GE VCT from August 2013 to August 2018 at our institution were selected. All lesions were proven either by surgery or by endoscopy guided aspiration or follow up. A total of 94 patients with proven diagnosis were selected. CT protocol for imaging pancreas includes triphasic scan which is an non-contrast study, arterial phase, a late arterial phase and a venous phase imaging. Triphasic CT protocol paves way for selective visualization of main arterial, venous structures, hence allowing assessment of vascular invasion by the tumour. Non-contrast study is done using $5 \mathrm{~mm}$ slice thickness with $2.5 \mathrm{~mm}$ reconstruction starting from the liver dome up to the iliac crests. Arterial phase is done with 2.5 mm slice thickness along with $1.25 \mathrm{~mm}$ reconstructions from top to bottom of liver at $20 \mathrm{sec}$ delay to obtain excellent hepatic arterial opacification with minimal contrast in portal vein. Immediately after arterial phase, at $40 \mathrm{sec}$ delay, pancreatic parenchymal phase/Late arterial phase is done. Portal venous phase is done using $5 \mathrm{~mm}$ slice thickness at 70 sec delay with $2.5 \mathrm{~mm}$ reconstructions. Incidence of various cystic lesions based on the histopathological findings, age and sex were analysed. The features of cystic lesions in the pancreas were studied like the overall size of the lesion, location, thickness of septation, nature of calcification, pancreatic duct dilatation if any, size of the largest cyst within the lesion, approximate number of cysts, presence of any solid component, nature of enhancement, presence of the wall and contour of the lesion were studied. 


\section{Statistical Analysis}

Descriptive statistics like percentage was used for analysis. Microsoft office 2007 was used.

\section{RESULTS}

Out of the total 94 patients, 50 patients had pseudocysts and 44 patients had neoplastic cysts proven by histopathology or endoscopy guided aspiration. The neoplastic cysts include 12 benign IPMT, 16 serous cystadenoma, 8 mucinous cystadenoma, 4 SPEN and 4 mucinous cystadenocarcinomata (chart-1). All the non-neoplastic cysts were pseudocysts and were predominantly seen in males than females with high prevalence between 41-50 yrs. All of them had association with acute or chronic pancreatitis. Most (58\%-22/38) of the benign neoplastic cysts were seen in females and all the 4 malignant cysts (mucinous cystadenocarcinomas) were seen in the males. All the SPEN were seen in females. About 75\% $(6 / 8)$ of the mucinous cystadenomas were female (chart - 2). All patients with mucinous cystadenoma were below 52 years and all the IPMT patients were above 54 years. Serous cystadenoma had even age distribution. All the SPEN were diagnosed before 30 years (chart -3). All the IPMT were seen in the head and body of the pancreas. 75\% (6/8) mucinous cystadenomas were seen in the tail of pancreas. $88 \%(14 / 16)$ serous cystadenomas were seen in the head and tail of the pancreas. All the SPEN were seen in the tail of the pancreas (chart-4).

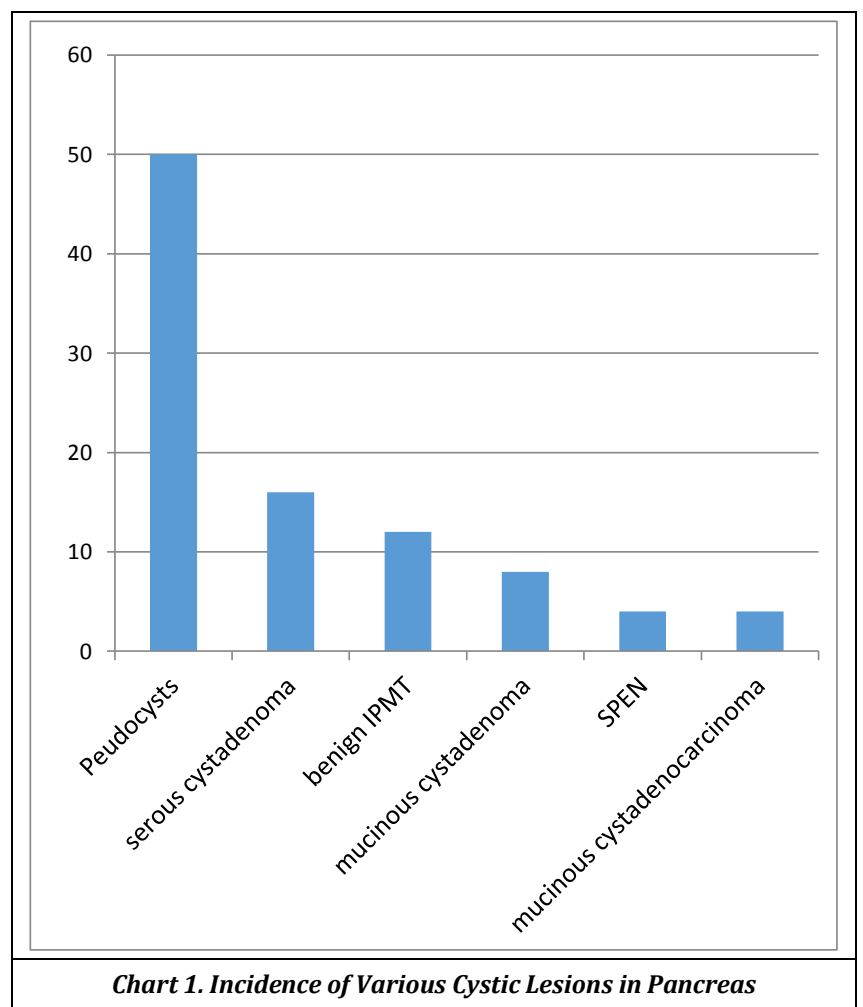

All SPEN were predominantly solid and had mild haemorrhage visualized in the plain scan. None of the other lesions had haemorrhage within it. The central necrotic areas were appearing cystic in these tumours. Thick septations $(>3$ $\mathrm{mm}$ ) were seen in all the mucinous cystadenocarcinomas. Benign lesions either had thin septations or no septations.
Out of the total 8 unilocular cysts without any septations, 6 had no visible wall and were finally diagnosed as IPMT and the remaining 2 had thin visible wall and were diagnosed as mucinous cystadenomas. Two patients had peripheral calcification, and both were diagnosed as mucinous cystadenomas. 6 patients had central chunky calcification and were diagnosed as serous cystadenomas 6 patients had diffuse mild dilatation of the main pancreatic duct and all were diagnosed as IPMT. 4 of these patients showed communication of the cyst with the dilated duct. One patient showed bulging major papillae. 6 patients had obstruction of the MPD with mild upstream dilatation, all of them were mucinous cystadenoma.
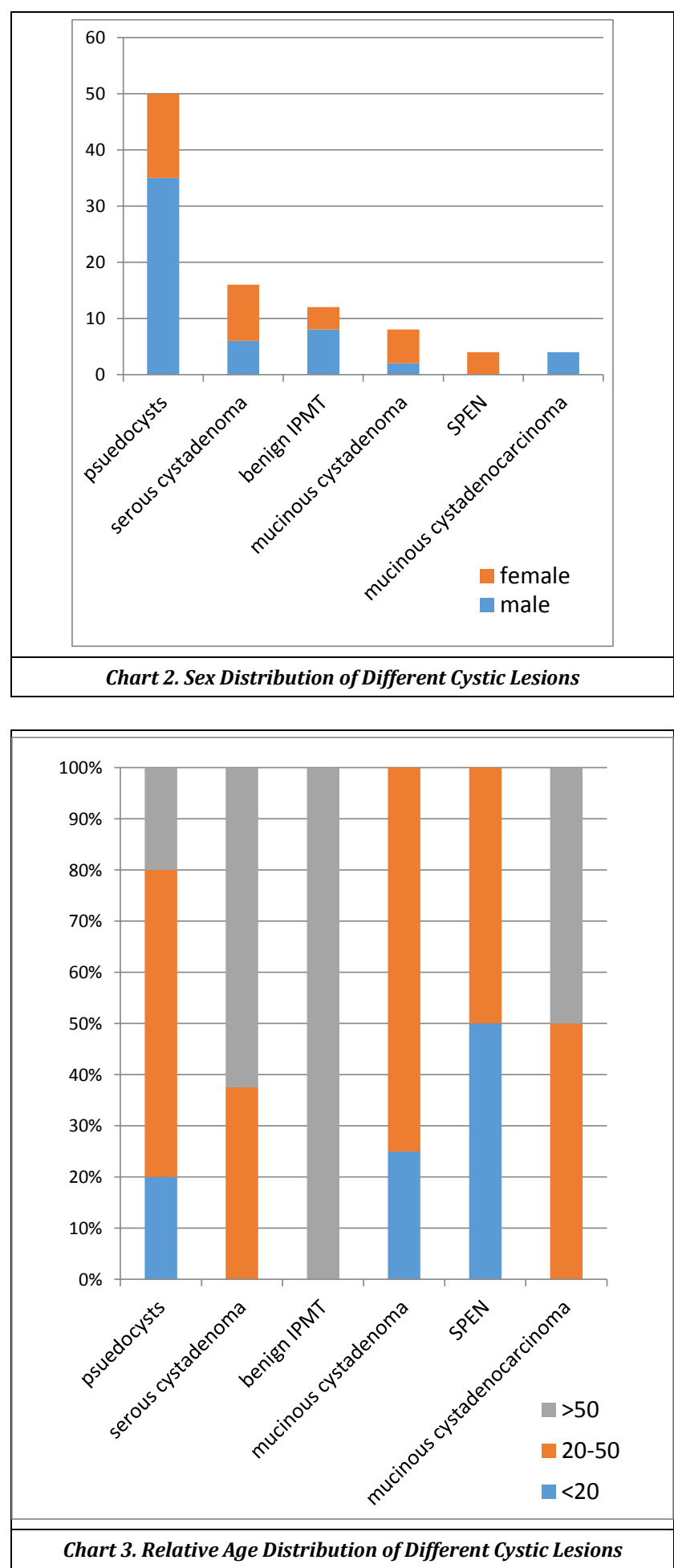


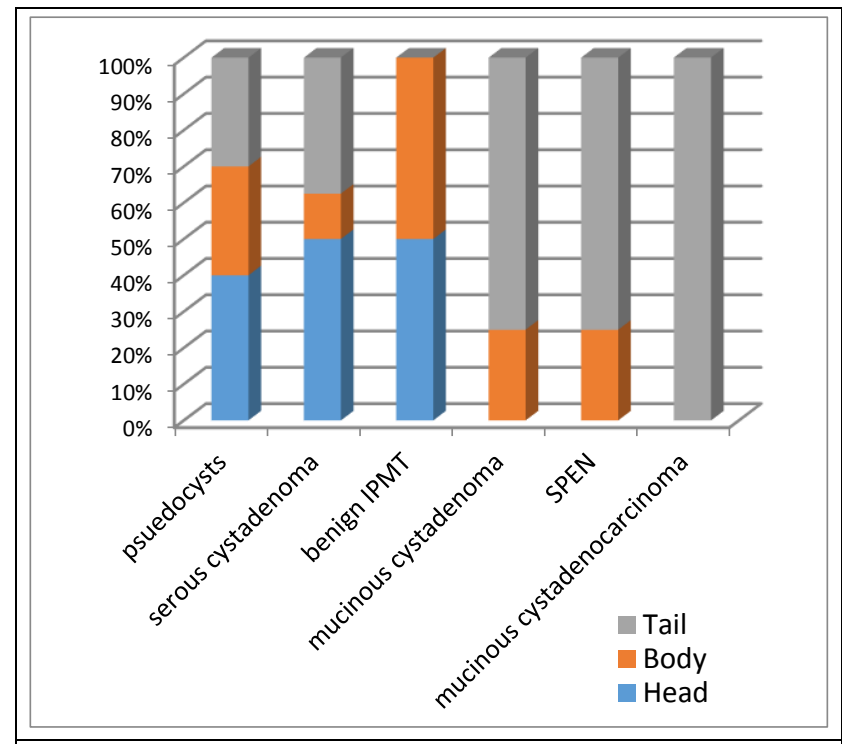

Chart 4. Location of the Cystic Lesions within the Pancreas

\begin{tabular}{|c|c|c|c|c|c|c|}
\hline $\begin{array}{c}\text { Sex } \\
\text { distribution }\end{array}$ & $\begin{array}{c}\text { Pseudo } \\
\text { cysts }\end{array}$ & $\begin{array}{c}\text { Serous } \\
\text { cystadenoma }\end{array}$ & $\begin{array}{c}\text { Benign } \\
\text { IPMT }\end{array}$ & $\begin{array}{c}\text { Mucinous } \\
\text { cystadenoma }\end{array}$ & SPEN & $\begin{array}{c}\text { Mucinous } \\
\text { cystadeno- } \\
\text { carcinoma }\end{array}$ \\
\hline Male & 35 & 6 & 8 & 2 & 0 & 4 \\
\hline Female & 15 & 10 & 4 & 6 & 4 & 0 \\
\hline \multicolumn{6}{|c|}{ Table 1: Gender Distribution of Various Benign } \\
and Malignant Cystic Lesions of Pancreas \\
\hline
\end{tabular}

\begin{tabular}{|c|c|c|c|c|c|c|}
\hline Age & $\begin{array}{c}\text { Pseudo- } \\
\text { cysts }\end{array}$ & $\begin{array}{c}\text { Serous } \\
\text { Cysta- } \\
\text { denoma }\end{array}$ & $\begin{array}{c}\text { Benign } \\
\text { IPMT }\end{array}$ & $\begin{array}{c}\text { Mucinous } \\
\text { Cysta- } \\
\text { denoma }\end{array}$ & SPEN & $\begin{array}{c}\text { Mucinous } \\
\text { Cystadeno- } \\
\text { carcinoma }\end{array}$ \\
\hline$<20$ years & 10 & 0 & 0 & 2 & 2 & 0 \\
\hline $\begin{array}{c}20-50 \\
\text { years }\end{array}$ & 30 & 6 & 0 & 6 & 2 & 2 \\
\hline$>50$ years & 10 & 10 & 12 & 0 & 0 & 2 \\
\hline
\end{tabular}

\begin{tabular}{|c|c|c|c|c|c|c|}
\hline $\begin{array}{c}\text { Location } \\
\text { within } \\
\text { Pan- } \\
\text { creas }\end{array}$ & $\begin{array}{c}\text { Pseudo- } \\
\text { cysts }\end{array}$ & $\begin{array}{c}\text { Serous } \\
\text { Cysta- } \\
\text { denoma }\end{array}$ & $\begin{array}{c}\text { Benign } \\
\text { IPMT }\end{array}$ & $\begin{array}{c}\text { Mucinous } \\
\text { Cystaden } \\
\text { oma }\end{array}$ & SPEN & $\begin{array}{c}\text { Mucinous Cysta- } \\
\text { denocarcinoma }\end{array}$ \\
\hline Head & 19 & 7 & 5 & 0 & 0 & 0 \\
\hline body & 15 & 3 & 6 & 2 & 1 & 0 \\
\hline Tail & 16 & 6 & 1 & 6 & 3 & 4 \\
\hline \multicolumn{7}{|c|}{ Table 3: Distribution of Lesions within the Pancreas } \\
\hline
\end{tabular}

Size of the biggest cyst within the lesion in all the serous cystadenomas were between 1 to $2 \mathrm{~cm}$. Most of the mucinous cystadenoma and cystadenocarcinomas (8/12- 67\%) had biggest cyst size $>2 \mathrm{~cm}$. All the IPMT had biggest cysts in the range of 0-2 cms. Solid component was visualized in all patients with mucinous cystadenocarcinoma $(n=4)$ and SPEN $(n=4)$. Mild enhancement of the solid component was seen in the venous phase images. No hyper vascularity seen in any of the cystic lesions. Pancreatic parenchymal phase images were ideal in studying the characteristics of cysts like nature of wall, septations and the cysts. Most of the IPMT (10/12-83\%) and serous cystadenoma (12/16-75\%) had no visible wall. About half of the patients $(6 / 14)$ with a visible wall were mucinous cystadenoma. Most of the mucinous cystadenoma (6/8- 75\%) had a smooth wall and most of the serous cystadenoma (14/16-88\%) and IPMT (10/12- 83\%) had lobulated wall. All the IPMT had few (1-2) cysts within the lesion. Most of serous cystadenomas (12/16-75\%) had more than 6 cysts and all the mucinous cystadenomas and cystadenocarcinomas had fewer than 6 cysts within the lesion.

\section{DISCUSSION}

Crippa et al reported IPMT accounted for 38\% of pancreatic cystic lesions, mucinous cystic neoplasm for $23 \%$, serous cystic neoplasm for $16 \%$ and SPEN about 3\%.[15] Fernandez et al reported serous and mucinous cystadenomas and mucinous cystadenocarcinoma comprise $>75 \%$ and IPMT constitute $\sim 21-30 \%$ of pancreatic cystic lesions.[16] In our study pseudocysts are the commonest overall cysts and serous cystadenoma is the commonest neoplastic cyst. Mucinous cystadenoma, serous cystadenoma and SPEN are common in females. IPMT and pseudocyst have equal sex distribution.[17] In our study IPMT and pseudocysts are common in males. Karoumpalis et al reported SPEN is seen at 20-40 years, mucinous cystadenoma between 40-50 years, serous cystadenoma between 50-70 years and IPMT between 60-70 years.[18] They further reported that IPMT is mainly seen in head and mucinous cystadenoma mainly in body and tail. No difference in distribution of the rest of the lesions within the pancreas.

IPMT is commonly seen in head (50\%), body (39\%), tail (7\%) and uncinated process (4\%).[16] Young reported $76.9 \%$ of mucinous cystadenomas and $54 \%$ of serous cystadenomas are seen in body and tail.[19] In our study most of mucinous cystadenoma are seen in the tail and the serous cystadenomas were equally distributed in head and tail of pancreas. IPMN is commonly smaller than $3 \mathrm{cms}$ whereas mucinous and serous cystic neoplasm, SPEN and pseudocyst are commonly $>3 \mathrm{cms} .{ }^{[17]} 73 \%$ of mucinous cystadenomas were round and $80 \%$ serous cystadenomas were lobulated and irregular. ${ }^{[19]}$ Pseudocysts are usually unilocular. But they can be rarely multiple in $10 \%$ of cases and sometimes also irregular and multilocular. Pseudocysts in acute pancreatitis is seen in $5-16 \%$ whereas in chronic pancreatitis it is seen higher in about $20-40 \%$.

Mucinous cystic neoplasm shows macrocystic lesion with few septations. [20] Serous cystadenomas are microcystic with honeycomb appearance. Rarely $7 \%$ are oligocystic or macrocystic. [19] Sun et al showed honeycomb pattern is seen in serous cystadenoma and side branch IPMT whereas none of the mucinous cystadenoma showed honeycomb pattern.[21] Honeycomb appearance is seen in serous cystadenomas and side branch IPMT but rarely has been reported in mucinous cystadenoma. ${ }^{[22]}$ Mucinous cystadenomas have thick $(>3 \mathrm{~mm})$ wall and serous cystadenomas have thin wall $(<3 \mathrm{~mm}) .78 .9 \%$ of serous cystadenoma show thin septations and $57 \%$ of mucinous cystadenomas show thick septations. Serous cystadenomas show $>2$ septae in $40 \%$ and mucinous cystadenomas show $<=2$ septae in $73 \%$. [19] Mucinous cystadenoma, IPMT, SPEN have malignant potential in descending order. Serous cystadenoma has very low malignant potential.

IPMT typically show communication with duct, mucinous cystadenoma shows occasional communication with duct and pseudocyst show frequent communication with duct.[18] Mucinous cystadenoma show mass effect over MPD with duct 
obstruction.[23] Small incidental cysts in asymptomatic patients correspond to side branch IPMT. Serous cystadenoma shows central calcification whereas mucinous cystadenoma show peripheral calcification. ${ }^{[23]}$ SPEN is seen in young women, well capsulated with varying amounts of haemorrhage. Atypical features are metastasis, duct obstruction, extracapsular spread, peripheral calcification, mimicking islet cell tumour and occurrence in male patient.[24]

EUS with FNA of the fluid improves the accuracy in differentiating the cystic lesions.[18] Due to partial volume averaging thin septations and small nodules within the cyst can be missed and hence a mucinous cystadenoma may be misdiagnosed as pseudocyst. Thin section CT with multiplanar reformats are helpful to differentiate.[17]

Main limitation of this study is not considering MRI for cyst characterization. MRI has advantage of demonstrating connection with MPD on T2 wt. image to differentiate IPMT from other tumours. MRI is useful in follow up because it lacks radiation exposure.[18,17]

\section{CONCLUSIONS}

Pseudocysts are the most common cysts of the pancreas followed by serous cystadenomas. Pseudocysts are associated with pancreatitis. Serous cystadenomas show a lobulated contour with an imperceptible wall containing smaller and multiple cysts and central chunky calcifications. Mucinous cystadenomas show a smooth contour, visible wall with peripheral rim calcifications and fewer bigger cysts. Malignant cysts show enhancing solid components. IPMT show duct dilatation with ductal communication, bulging papillae and are mostly unilocular without any visible wall. SPEN is seen in young females with solid areas, necrosis and haemorrhage. Hence, CT features help in characterizing the different cystic lesions of the pancreas.

\section{REFERENCES}

[1] Sheehan MK, Beck K, Pickleman J, et al. Spectrum of cystic neoplasms of the pancreas and their surgical management. Arch Surg 2003;138(6):657-60.

[2] Fernandez-del CC, Warshaw AL. Cystic tumors of the pancreas. Surg Clin North Am 1995;75(5):1001-16.

[3] Curry CA, Eng J, Horton KM, et al. CT of primary cystic pancreatic neoplasms: can CT be used for patient triage and treatment? AJR Am J Roentgenol 2000;175(1):99103.

[4] Irie $\mathrm{H}$, Honda $\mathrm{H}$, Aibe $\mathrm{H}$, et al. $\mathrm{MR}$ cholangiopancreatographic differentiation of benign and malignant intraductal mucin-producing tumors of the pancreas. AJR Am J Roentgenol 2000;174(5):1403-8.

[5] Sahani DV, Kadavigere R, Saokar A, et al. Cystic pancreatic lesions: a simple imaging-based classification system for guiding management. Radiographics 2005;25(6):1471-84.

[6] Barresi L, Tarantino I, Granata A, et al. Pancreatic cystic lesions: how endoscopic ultrasound morphology and endoscopic ultrasound fine needle aspiration help unlock the diagnostic puzzle. World J Gastrointest Endosc 2012;4(6):247-59.

[7] Boraschi P, Donati F, Cervelli R, et al. Secretin-stimulated MR cholangiopancreatography: spectrum of findings in pancreatic diseases. Insights Imaging 2016;7(6):819-29.

[8] Khan A, Khosa F, Eisenberg RL. Cystic lesions of the pancreas. American Journal of Roentgenology 2011;196(6):W668-W77.

[9] Kim DH, Pickhardt PJ. Radiologic assessment of acute and chronic pancreatitis. Surg Clin North Am 2007;87(6):1341-58.

[10] Sarr MG, Murr M, Smyrk TC, et al. Primary cystic neoplasms of the pancreas: neoplastic disorders of emerging importance-current state-of-the-art and unanswered questions. J Gastrointest Surg 2003;7(3):417-28.

[11] Pitman MB, Lewandrowski K, Shen J, et al. Pancreatic cysts: preoperative diagnosis and clinical management. Cancer Cytopathol 2010;118(1):1-13.

[12] European Study Group on Cystic Tumours of the Pancreas. European evidence-based guidelines on pancreatic cystic neoplasms. Gut 2018;67(5):789-804.

[13] Hruban RH, Pitman MB, Klimstra DS. Atlas of tumor pathology. Washington, DC: American Registry of Pathology and Armed Forces Institute of Pathology 2007.

[14] van Asselt SJ, de Vries EG, van Dullemen HM, et al. Pancreatic cyst development: insights from Von HippelLindau disease. Cilia 2013;2(1):3.

[15] Valsangar NP, Morales-Oyarvide V, Thayer SP, et al. 851 resected cystic tumors of the pancreas: a 33-year experience at the Massachussets general hospital. Surgery 2012;152(3 Suppl 1):S4-S12.

[16] Fernández-del Castillo C. Mucinous cystic neoplasms. J Gastrointest Surg 2008;12(3):411-3.

[17] de Jong K, Bruno MJ, Fockens P. Epidemiology, diagnosis, and management of cystic lesions of the pancreas. Gastroenterol Res Pract 2012;2012:147465.

[18] Karoumpalis I, Christodoulou DK. Cystic lesions of the pancreas. Ann Gastroenterol 2016;29(2):155-61.

[19] Kim YH, Saini S, Sahani D, et al. Imaging diagnosis of cystic pancreatic lesions: pseudocyst versus nonpseudocyst. Radiographics 2005;25(3):671-85.

[20] Tseng JF, Warshaw AL, Sahani DV, et al. Serous cystadenoma of the pancreas: tumor growth rates and recommendations for treatment. Ann Surg 2005;242(3):413-21.

[21] Sun Y, Zhou F, Liu F, et al. Discrimination of serous cystadenoma from mucinous cystadenoma in the pancreas with contrast-enhanced ultrasonography: a prospective study in 61 patients. Onco Targets Ther 2017;10:1285-94.

[22] Jefferson B, Venkatraman I, Kumar RV, et al. Mucinous cystadenoma of pancreas with honeycombing appearance: radiological-pathological correlation. Indian J Radiol Imaging 2018;28(3):327-9.

[23] Gore RM, Wenzke DR, Thakrar KH, et al. The incidental cystic pancreas mass: a practical approach. Cancer Imaging 2012;12(2):414-21.

[24] Choi JY, Kim MJ, Kim JH, et al. Solid Pseudopapillary tumor of the pancreas: typical and atypical manifestations. Am J Roentgenol 2006;187(2):W178-86. 